\title{
The (Sub-Optimal) Use of Technological Innovation by Public Healthcare Organization Management: A Literature Review
}

\author{
Vincenzo Sforza \\ Department of Economy, Engineering \\ Society and Business \\ University of Tuscia-Viterbo \\ Via del Paradiso, 47 - 01100 Viterbo, Italy \\ Riccardo Cimini \\ Department of Economy, Engineering, Society and Business \\ University of Tuscia-Viterbo, Italy
}

\begin{abstract}
In the light of the European Commission's (2017) request to introduce innovative solutions, to rethink the organization of national health systems, and to ensure their sustainability, resilience, and effectiveness, this work provides a systematic analysis of the literature on technological innovation for the management of public healthcare organizations. Following the Preferred Reporting Items for Systematic Reviews and Meta-Analyses (PRISMA) protocol, the research examines 100 articles published in scientific journals between 1989 and 2019. The paper provides evidence of increased interest among academics and editors in this multidisciplinary topic. It offers insights for future research, mainly because of the critical organizational and economic issues linked to the diffusion of technological innovations and the financial constraints under which public healthcare systems currently operate (e.g., short-term-focused budgets). Findings identify factors that can eliminate constraints that obstruct the diffusion of innovation and respond to the European Commission's invitation to enable the digital transformation of health and care in the Digital Single Market, "empowering citizens and building a healthier society" (EU, 2018). A minimal number of publications has focused on the effect of innovation on management. There is room to improve its role, considering that most such publications emphasize technical, engineering/medical, cultural, and organizational conditions.
\end{abstract}

Keywords: technological innovation, healthcare organizations, senior management decisions, obstacles to innovation, systematic literature review

\section{Introduction}

A recent document from the European Commission (EU, 2017), issued after a thorough examination of the characteristic features of the health systems of European Union (EU) member states, highlights the need to rethink health systems' organization to ensure, in the medium and long term, both sustainability and resilience, as well as the effectiveness of the health services provided. The progressive aging of the population, the increase in chronic diseases, and the incidence of polypathologies, the change in people's lifestyles and living conditions, the recessive dynamics of the economic system, and the policies to contain public expenditure are some of the challenging factors that require a search for innovative solutions.

The European Commission (EC) has assigned a leading role to the implementation of technological innovation by defining a general strategy for development of the Digital Single Market. To manage healthcare organizations effectively and efficiently through the use of technological innovation tools, the EC has also published, in the context of the health sector, a Staff Working Document (EU, 2018a) and a "Communication on Digital Transformation of Health and Care in the Digital Single Market" (EU, 2018b). This topic is of increasing interest in a wide range of scientific journals and presents strong interdisciplinarity covering medical, biotechnological, engineering, economic, and management issues.

This work aims to provide a systematic literature review (SLR) with a mixed quantitative/qualitative approach to take stock of the studies carried out to date and identify possible future research opportunities. The proposed mixed study review is not a novelty in the literature, as highlighted by the taxonomy of Grant and Booth (2009, pp. 94-96) and by the use of both approaches in similar studies (e.g., Gonçales Filho et al., 2016; Xu et al., 2018). Systematic analysis of the literature enables the investigation of the critical characteristics of the scientific products analyzed, such as type of 
publication, year, journal and its impact factor, country of author(s), research methodology, and theme of interest. This is useful for identifying the main research threads, giving scholars and the professional world the opportunity to sift through the results and to gather ideas for future research or operational applications. The analysis was conducted following the Preferred Reporting Items for Systematic Reviews and Meta-Analyses (PRISMA) protocol that Moher et al. (2009) proposed; PRISMA is widely used in similar studies (e.g., MacLure, 2014; Tam et al., 2017).

Based on these premises, the main research questions of this paper are as follows: 1) When, by whom, and where are the papers written on the use of technological innovation for managers of public healthcare organizations? 2) What research has the highest number of citations in the scientific community of scholars who have deepened the issues related to the use of technological innovation in public healthcare organizations? Which kinds of contexts have been studied?

The paper continues as follows. The next section presents the background. In the third section, our methodological approach is detailed. In the fourth section, the overall findings of the systematic review are summarized to answer our research questions. The fifth section is dedicated to discussion of the research findings, while the last section contains concluding remarks, limitations of the paper, and opportunities for possible future research.

\section{Background}

Scholars, practitioners, and policymakers consider technological innovation as one factor of strategic importance to ensure the current and future effectiveness, sustainability, and resilience of public health systems. Indeed, in the current global framework for reducing public expenditure, these systems must respond to the increase in health needs dictated by demographic changes, the lengthening of life expectancy, and the higher incidence of chronic diseases. For example, in the Eurozone, public expenditure on healthcare and long-term care, which in 2015 was, on average, around $8.5 \%$ of gross domestic product (GDP), is expected to increase by between 2 and 4 percentage points by 2060 (European Commission, 2015b, 2016). This scenario requires a rethinking of how health services are organized and managed. The implementation of new technologies, from this point of view, has long encouraged the spread of new ways to offer health services. Possible examples are telemedicine (Perednia\& Allen, 1995), robotic and telerobotic surgery (Ballantyne, 2002), electronic health records (Jha et al., 2009; Blumenthal \&Tavenner, 2010), and the possibility of integrating more specialists - virtual healthcare teams - providing remote consultations to primary care (Pitsillides et al., 2006).

The neologism eHealth, which concerns the use of information and telecommunication technologies for the prevention, diagnosis, and treatment of diseases and human health management, has become widespread (WHO, 2006). Due to its many variations, this term has been the subject of a specific SLR on its definition in the literature (Oh et al., 2005). Moreover, the breadth of the possibilities offered by the implementation in the health sector of instruments promoted by technological innovation is confirmed by the presence of several SLRs on this issue (Roine et al., 2001; Whitten et al., 2002; Ekeland et al., 2010; Cresswell\& Sheikh, 2013). Technological innovation is promoted by the considerable development of innovative medical solutions. Examples are offered by web-based online technologies such as medical online networks and medical teleconsultation sites (Whalther et al., 2005), from monitoring technologies of physiological parameters offered by wearable devices (Metcalf et al., 2016) to those resulting from the use of artificial intelligence in medical diagnostics (Hamet\& Tremblay, 2017).

The opportunity to collect and process large amounts of medical data (big data, big data analytics) generated by different sources (Murdoch \&Detsky, 2013) is a catalyst for the implementation of technological innovation. This amount of data must be integrated and made available for more effective prevention, to ensure faster diagnosis, to tailor treatment (improving its effectiveness), and to reduce the hospitalization rate by following patients outside the hospital after the acute phase. To ensure the effectiveness of innovation, it is essential to consider the role of health data for users at the heart of innovation strategies. Unfortunately, the European Commission (2018b, p. 1ff) has pointed out that health data are not managed in the same way by the various EU countries, or within the various national health systems, either for technical reasons - communications between different data management applications - or for organizationaladministrative reasons. For example, in Italy, according to article 29, point g, of Legislative Decree No. 118/2011, it is compulsory for the various regions to assess their healthcare organizations' state of risk, and adequate provision for that risk must be made. Empirical evidence has shown that regional databases on health risks have often been established based on the (supposed) best accounting practices and applications among organizations of the area. As these databases are not designed with a common framework, they do not allow for the full sharing of data between regions, which would be useful for both development of the most appropriate risk management policies and the correct application of provisions in the balance sheet of healthcare organizations. 
Aware of the obstacles to the spread of technological innovations, the European Commission intervened regardingthe critical factors for data integration. A specific public consultation recognized as a priority the development of European standards to ensure the quality, reliability, and information technology (IT) security of health data and the interoperability of applications through an exchange of open formats.

The adoption of technologies and, more generally, the diffusion of innovation are among the themes most studied by scholars (e.g., Brandyberry, 2003; MacVaugh and Schiavone, 2010). Based on Rogers' (1962) theory of adoption and diffusion of innovations, several studies focused on critical factors that can inhibit the spreading of new technologies. According to MacVaugh\& Schiavone (2010, p. 199ff), the evaluation of their adoption "takes a shape in multiple contextual domains", which may concern the industry/market, the community of users, and the single user. It is challenging to measure the influence that the determinants, which typically enable adoption for innovations, have in the multiple contextual domains of the public healthcare sector. At a macro level, indeed, for Atun\& Sheridan (2007, p. vvi) this sector "operates in a uniquely complex social, political and ethical environment, ... characterized by involvement of the state to prevent market failure". Even with differentiations that depend on the institutional context, this involvement covers various fields (e.g., regulation, public policy development, collection and resources allocation, purchase or delivery of healthcare services, among others). At a micro level, significant environmental pressures affect healthcare organizations (Pauget\& Wald, 2018). According to Schultz et al. (2012), their innovativeness is affected by a combination of formal and informal organizational mechanisms.

These factors claim for a literature systematization to identify the influence of particular conditions of adoptionof technology in the public healthcare sector. This issue is also topical for the consequences of the recent financial crisis and the subsequent budgetary constraints of governments (Freeman \& Moran, 2000; Anell, 2005; Appleby, 2008; Orszag \& Emanuel, 2010; Jordan \&Battaglio, 2014; Popescu, 2014).

\section{Methodology}

The systematic analysis of literature was first applied in the medical sciences and then extended to business (e.g., Denyer\& Neely, 2004; Broadbent \& Guthrie, 2007; Dumay, 2018; Massaro, Dumay, \& Guthrie, 2016), and innovation studies (e.g., MacVaugh\& Schiavone, 2010; Spender et al., 2017). The conditions for development of the so-called systematic reviews are found in the early 1990 diffusion in the United States of the interdisciplinary approach called "practice based on scientific evidence (evidence-based practice, EBP)" (Cochrane, 1972). In this approach, decisions concerning professional practice (e.g., first in the clinical field and then in the other fields of medicine, nursing, and psychology, among others) should have been based on scientific studies and research to ensure that patients are treated according to "efficacy tests" that can be traced back to previous successful trials. Over time, factors such as the increase in the number of publications, research methodologies, and purposes for which a literature analysis may be necessary for a given subject (e.g., identifying prevailing theories, synthesizing a topic of study, guiding future research) have led to a flowering of literature review models. According to Massaro etal. (2016), such models develop along a continuum - as shown in Figure 1- which starts from those marked by a substantial absence of rules (cd. rapid review) and continues to those with the strictest protocols to follow (cd. structured literature review).

Figure 1. The continuum of literature review models (Source: Massaro et al., 2016, p. 769)

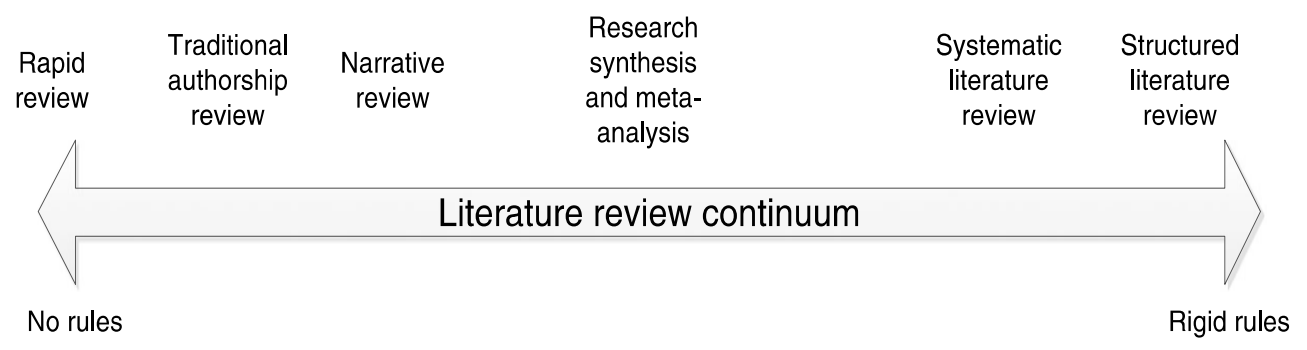

To answer the research questions, the methodological choice has fallen on a systematic literature review, organized according to a mixed quantitative/qualitative approach. An SLR offers better possibilities than a narrative literature review or a meta-analysis (and, even more so, the rapid review or traditional authorship review) in the study of subjects in which wider scientific literature exists (Mulrow, 1994). Another advantage of the SLR - which, however, requires more working time - is that it can reduce the risk of distortions related to the subjectivity spaces of the less structured models, thanks to the use of strict, transparent, and replicable protocols (Cook et al., 1997). For this reason, it was not considered necessary to use the more rigid structured literature review model (Broadbent \& Guthrie, 2007;Dumay, 2016; Dumay, 2018; Massaro et al., 2016) to answer the research questions. 
Considering the plethora of possible protocols, this work has been carried out following the PRISMA protocol Moher et al. (2009) proposed; this protocol is recommended by numerous journals specialized in the medical area. The protocol requires that the work be divided into the following phases: 1) Data collection; 2) Data analysis; 3) Summary of findings.

\subsection{Phase 1: Data collection}

The first phase of the work covered the following sequence of activities: (a) conduct database search, (b) establish timeframe, (c) read abstracts, and (d) seek expert opinion.

The first step of this phase (conduct database search) concerned the selection of the research database from which to extract the list of scientific publications to be considered. To this end, SCOPUS was chosen because it is recognized, as Elsevier specifies on its website, as "the largest abstract and citation database of peer-reviewed literature." The data extraction, initially in March 2019 and repeated in May, was carried out by entering the terms "technological innovation" (Level 1 search string) AND "manage*" (Level 2 search string) AND "healthcare organization*" OR "healthcare organisation" (Level 3 search string) to search for such words in the titles and abstracts of scientific publications. Only articles published in scientific journals were considered for the review process. Following Rothstein and Hopewell's (2009) proposal, to maintain high-quality standards, we omitted the literature on scientific products that had not completed their maturation (conference paper and conference review) or had limited thickness of the contained speculations (notes and short survey). Finally, to address the need to assess the impact of publications to answer the second research question, books and book chapters were excluded due to the lack of data on citations.

As a second step (establish timeframe), the model foresees the possible limitation of the time horizon to be analyzed. This limitation must be defined according to the purpose of the revision and the content of research questions. The data extraction of the first phase used a 30-year horizon (1989-2019). With regard to the objective of constructing an SLR on the managerial effects of technological innovation in healthcare organizations and having examined the results of similar SLRs published in previous years, the whole set was submitted to the review, without making any cut with respect to year of publication (timeframe). However, compared to the reviews providing for the exclusion of the last (incomplete) year (e.g., Massaro, 2015; Massaro, Dumay, \& Guthrie, 2016), in this paper, the analysis also includes articles published through May 2019 - time of the last extraction of data - to analyze the entire 30 years with the data available at the time of the collection phase of our research protocol.

The third step of the protocol (read abstracts) made it possible to remove from the review all those scientific works in which, from reading abstracts, it was clear that the terms "technological innovation," "manage*" and "healthcare organiz(s)ation" were mentioned incidentally and, therefore, our theme of analysis was not the main subject of such publications.

The last step (seek expert opinion) was to share the dataset with a technological innovation expert in healthcare organizations to verify the list of items to be subject to Phase 2 of the revision and to identify any reference items not considered.

\subsection{Phase 2: Data analysis}

For analysis of the selected articles in the first phase, the methodology Cooper (2010) suggested was followed. In this respect, 70 variables have been identified regarding the characteristics of authors, scientific journals, and scientific articles to be reviewed. The most common functions of the software Excel were used to answer the questions. The correlation coefficients for the citation analysis have been calculated with the software Stata. A dummy variable for average health expenditure per capita for the years 2010-2016 was obtained from data on annual health expenditure collected by the World Bank (World Development Indicators).

\subsection{Phase 3: Summary of findings}

The last phase of the review process is the so-called synthesis, which is necessary to provide an essential overview of the results obtained based on the examination of several variables. At this stage, we have processed the results, which are described more extensively in Section 4. In particular, in sub-section 4.1, the data of the article selection process are presented; in sub-section 4.2 the results of the review are presented concerning the authors and scientific journals that have taken an interest in the issue (in response to the first research question). Sub-section 4.3 highlights an overview of the "top 10 articles" (in response to the second research question) to examine publications with the highest number of citations, consistent with similar literature works (Bisognoet al., 2018; Dumay, 2016; Dumay, 2018).

\section{Results}

\subsection{Article selection}


According to the research protocol, the extraction of articles from the SCOPUS database is accomplished by searching in the titles or abstracts for the keywords "technological innovation" AND "manage*" AND "healthcare organization*" OR "healthcare organisation." The extraction returned 198 titles relating to scientific products (first step).

The composition of these products was as follows: (a) Article\&review, 143 observations, (b) Conference paper, 34 observations, (c) Conference review, 3 observations, (d) Book, 3 observations, (e) Book chapter, 11 observations, (f) Note, 2 observations, and (g) Short survey, 2 observations. Consistent with the protocol outlined in sub-section 3.1, the review process was initiated exclusively for the class "Article \& review" (143 observations). The extracted articles have been published over a period of 30 years (1989-2019). Taking into account the purpose of constructing an SLR on the managerial effects of technological innovation in healthcare organizations, and having examined the results of similar SLRs published in previous years, the whole set to the revision was submitted, without any cut compared to the years of the publications (timeframe step). The subsequent reading of abstracts instead allowed us to eliminate 53 publications in which our subject was not found to be the main argument (read abstracts step). In these papers, the keywords "technological innovation," "manage*", and "healthcare organiz(s)ation*" have only been used incidentally. Following a comparison with an expert, the number of articles was supplemented by 10 additional publications (expert opinion step). Therefore, the products under investigation numbered 100.

\subsection{Time evolution, authors, affiliations, journals}

The first part of the first research question analyzes "when, by whom, and where" the publications on the managerial implications of technological innovation in public healthcare organizations were written. Figure 2 shows that from the first publication of our dataset (1989) until today, the theme has found growing space in scientific journals, especially since 2006, with a peak in 2014. Data for 2019 are provisional.

Figure 2. Evolution over time of published articles (absolute and cumulative number)

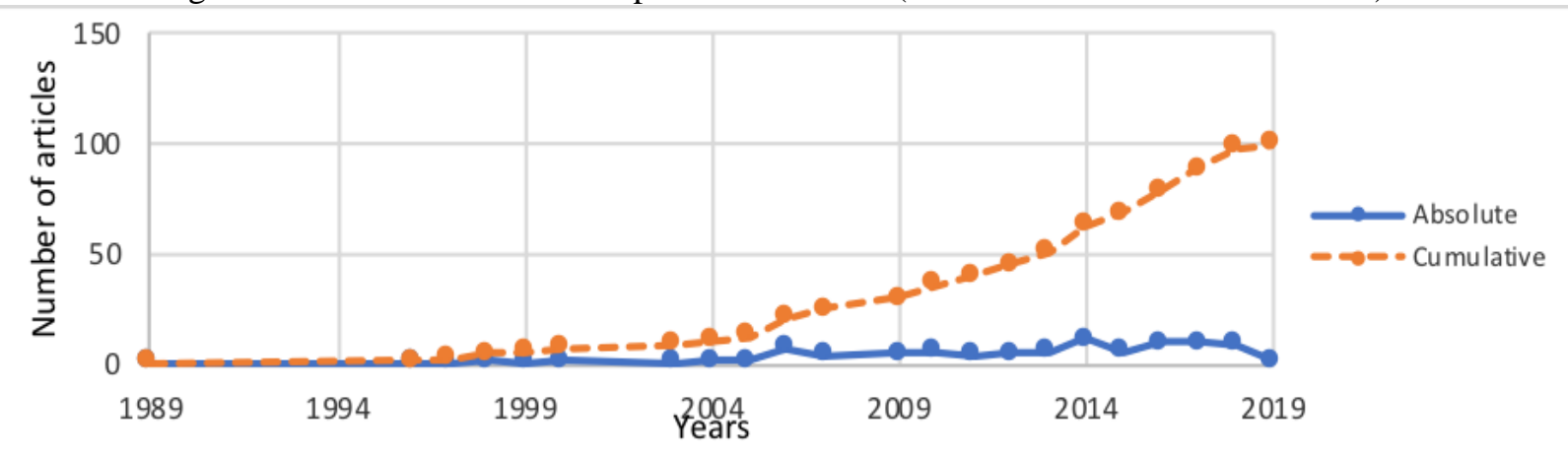

Table 1 shows, in turn, the temporal distribution of publications in relation to the number of authors, distinguished according to university affiliation in "academic" and "non-academic" fields.

Table 1. Evolution over time of published articles by academics and non-academics (absolute number)

\begin{tabular}{|c|c|c|c|c|c|c|c|c|c|c|c|c|c|c|c|c|c|c|c|c|c|c|c|}
\hline Years & $\stackrel{\circ}{2}$ & ஃั & $\hat{2}$ & $\stackrel{\infty}{2}$ & よे & 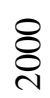 & ڤి & ষ্ণ & $\stackrel{\wp}{8}$ & ஜ̊ & है & ஓి & 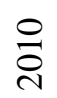 & $\overline{\bar{̊}}$ & $\stackrel{\overbrace{}}{\check{N}}$ & $\stackrel{m}{\stackrel{n}{\circ}}$ & 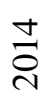 & $\frac{n}{2}$ & $\stackrel{0}{\circ}$ & 홍 & $\stackrel{\infty}{\stackrel{N}{\circ}}$ & อิ & Tot \\
\hline $\begin{array}{l}\text { No. of } \\
\text { Authors }\end{array}$ & 2 & 2 & 1 & 1 & 1 & 2 & 2 & 9 & 3 & 16 & 6 & 12 & 18 & 11 & 19 & 26 & 58 & 15 & 107 & 33 & 34 & 5 & 383 \\
\hline Academics & 0 & 0 & 0 & 1 & 0 & 0 & 1 & 3 & 2 & 10 & 5 & 2 & 10 & 7 & 11 & 18 & 47 & 12 & 52 & 29 & 21 & 5 & 236 \\
\hline $\begin{array}{l}\text { Non- } \\
\text { academics }\end{array}$ & 2 & 2 & 1 & 0 & 1 & 2 & 1 & 6 & 1 & 6 & 1 & 10 & 8 & 4 & 8 & 8 & 11 & 3 & 55 & 4 & 13 & 0 & 147 \\
\hline
\end{tabular}

The (100) papers considered in our review represent 383 co-authorships, promoted in 61.6\% of cases (236 observations) by affiliation with university institutions, and the remaining 38.4\% (147 observations) come from persons outside the university (non-university hospital doctors, biomedical engineers, managers of public institutions, managers of pharmaceutical companies, and managers of electromedical medical companies). This issue is interesting when compared with that of SLRs developed on other topics of investigation, where the contribution of the so-called "practitioners" has a weight equal to or less than 5\% of the total (e.g., Dumay et al., 2015, p. 270;Dumay et al., 2016, p. 172; Massaro et al. [2], 2016, p. 262). The data show that the theme was initially studied in the professional field, while the number of academics who have dealt with the subject has become significant and stable, especially after 2010. Altogether, the average number of authors per publication was 3.91, and in $34 \%$ of cases, the papers were the joint result of mixed groups (academic/non-academic). The number of co-authors per publication is particularly high (almost double) compared to the number of SLRs mentioned above (e.g., Dumay et al., 2018, p. 1517). An analysis of the 
identifiers of each author made it possible to verify 368 co-authors; in $96.5 \%$ of cases (355 observations), they participated in the production of a single scientific publication, while the remaining $3.5 \%$ (13 observations) participated in up to a maximum of three works.

Regarding the information on the nationality of the institution declared by the authors, the data show that about $53 \%$ of affiliates is linked to universities and institutions in the United States (107 out of 383 observations), Italy (50 out of 383 observations), and the United Kingdom (45 out of 383 observations). Analyzing the country factor, with particular reference to the average health expenditure per capita incurred in the period 2010-2016 (source: World Bank, World Health Organization Global Health Expenditure database), one can see that $91.2 \%$ of the distribution of the authorships is tied to institutions with centers in countries in which the health expenditure is higher than the world average for the same period $(\$ 1,193.73)$.

As for the editorial placement of the selected papers, these have been published in as many as 80 academic journals. A cross-check with SCImago's Journal Rank (SJR) shows that these are predominantly in the medical, health policy, and public health area; the topic is also widespread in engineering journals and in those that deal with technology and innovation management in the business and management area.

\subsection{Analysis of citations and the "top 10" articles}

This section highlights the results of the analysis of the citation impact to answer the second research question: What research has the highest number of citations in the scientific community of scholars who have deepened the issues related to the use of technological innovation in public healthcare organizations? Which kinds of contexts have been studied? Figure 3 shows that it is not necessarily the less recent articles that have the most citations; on the contrary, the most cited articles have been published in the last 10 years (of the 30 years of our time horizon). A possible explanation is the marked obsolescence of the technologies applied to the healthcare sector. Because scholars normally publish their results of case studies on new technological innovation experiments, such work has a life cycle necessarily shorter than that of other themes.

Figure 3. Distribution of citations by year of publication

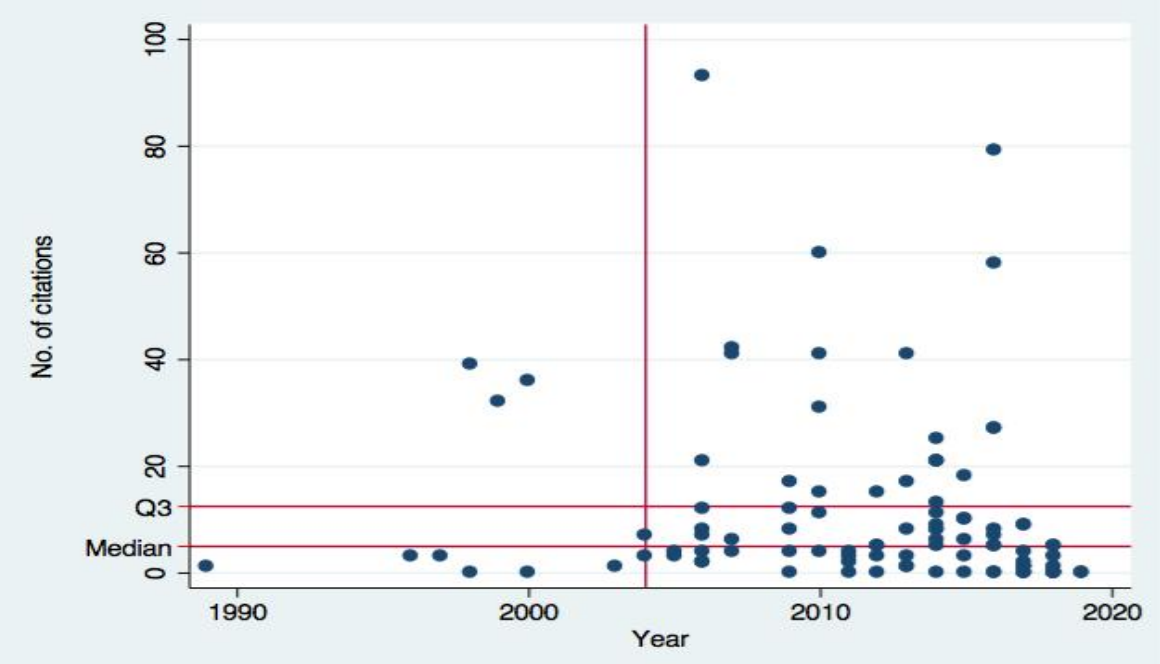

To broaden the impact analysis, we can relate the number of citations to the quality of the journals. In our case, this search returns a positive correlation, as it was imaginable according to the logic of construction of the parameters of the impact factor. In particular, the following Pearson correlation coefficients were recorded: a) Distribution of the number of citations and journal's CiteScore ${ }^{\mathrm{TM}} 2018$ : 0.4927*; b) Distribution of the number of citations and journal's SJR 2018: $0.3054 *$; c) Distribution of the number of citations and journal's Source Normalized Impact per Paper (SNIP) 2018: $0,2590^{*}$.

Following our research protocol, we have identified dataset papers with the most significant impact in the scientific community. To this end, the citations in Google Scholar (through August 12, 2019) were considered. This practice has been widely followed in the SLRs mentioned above (e.g., Bisogno et al., 2018, p. 14). The analysis led to populating the two "top 10" given in Tables 2 and 3, relative, respectively, to the citations in absolute value and per year. 
Table 2. Top ten articles by Google Scholar citations

\begin{tabular}{|c|c|c|c|c|}
\hline No. & & Articles & Year & Cit. \\
\hline 1 & Barlow, J. et al. & $\begin{array}{l}\text { Implementing complex innovations in fluid multi-stakeholder } \\
\text { environments: Experiences of 'telecare' }\end{array}$ & 2006 & 179 \\
\hline 2 & Petroni, A., & $\begin{array}{l}\text { The analysis of dynamic capabilities in a competence-oriented } \\
\text { organization }\end{array}$ & 1998 & 149 \\
\hline 3 & Auffray, C., et al. & $\begin{array}{l}\text { Making sense of big data in health research: Towards an EU } \\
\text { action plan }\end{array}$ & 2016 & 118 \\
\hline 4 & Vest, J.R. & $\begin{array}{l}\text { More than just a question of technology: Factors related to } \\
\text { hospitals' adoption and implementation of health information } \\
\text { exchange }\end{array}$ & 2010 & 111 \\
\hline 5 & Bernstein, M.L. et al. & $\begin{array}{l}\text { Five constants of information technology adoption in } \\
\text { healthcare }\end{array}$ & 2007 & 104 \\
\hline 6 & $\begin{array}{l}\text { Deluca, J.M., \&Enmark, } \\
\text { R. }\end{array}$ & E-health: the changing model of healthcare & 2000 & 96 \\
\hline 7 & Fonseca, V.A. et al. & $\begin{array}{l}\text { Continuous glucose monitoring: A consensus conference of } \\
\text { the American association of clinical endocrinologists and } \\
\text { American College of endocrinology }\end{array}$ & 2016 & 91 \\
\hline 8 & Al-Qirim N. & $\begin{array}{l}\text { Championing telemedicine adoption and utilization in } \\
\text { healthcare organizations in New Zealand }\end{array}$ & 2007 & 89 \\
\hline 9 & Trueman, P. et al. & $\begin{array}{l}\text { Coverage with evidence development: Applications and } \\
\text { issues }\end{array}$ & 2010 & 71 \\
\hline 10 & Nilashi, M. et al. & $\begin{array}{l}\text { Determining the importance of Hospital Information System } \\
\text { adoption factors using Fuzzy Analytic Network Process } \\
\text { (ANP) }\end{array}$ & 2016 & 57 \\
\hline
\end{tabular}

(As at August 18, 2019)

Table 3. Top ten articles citation per year (CPY)

\begin{tabular}{|c|c|c|c|c|}
\hline No. & & Articles & Year & $\mathrm{CPY}$ \\
\hline 1 & Auffray, C. et al. & $\begin{array}{l}\text { Making sense of big data in health research: Towards an EU } \\
\text { action plan }\end{array}$ & 2016 & 39.3 \\
\hline 2 & Fonseca, V.A. et al. & $\begin{array}{l}\text { Continuous glucose monitoring: A consensus conference of the } \\
\text { American association of clinical endocrinologists and American } \\
\text { College of endocrinology }\end{array}$ & 2016 & 30.3 \\
\hline 3 & Nilashi, M. et al. & $\begin{array}{l}\text { Determining the importance of Hospital Information System } \\
\text { adoption factors using Fuzzy Analytic Network Process (ANP) }\end{array}$ & 2016 & 19.0 \\
\hline 4 & Barlow, J. et al. & $\begin{array}{l}\text { Implementing complex innovations in fluid multi-stakeholder } \\
\text { environments: Experiences of 'telecare' }\end{array}$ & 2006 & 13.8 \\
\hline 5 & Vest, J.R. & $\begin{array}{l}\text { More than just a question of technology: Factors related to } \\
\text { hospitals' adoption and implementation of health information } \\
\text { exchange }\end{array}$ & 2010 & 12.3 \\
\hline 6 & Graffigna, G. et al. & Positive technology as a driver for health engagement & 2013 & 9.0 \\
\hline 7 & Kerr, D. et al. & Diabetes and technology in 2030: a utopian or dystopian future? & 2018 & 9.0 \\
\hline 8 & Bernstein, M.L. et al. & Five cor & 2007 & 8.7 \\
\hline 9 & Trueman, P. et al. & Coverage with evidence development: Applications and issues & 2010 & 7.9 \\
\hline 10 & Al-Qirim, N. & $\begin{array}{l}\text { Championing telemedicine adoption and utilization in healthcare } \\
\text { organizations in New Zealand }\end{array}$ & 2007 & 7.4 \\
\hline
\end{tabular}

(As at August 18, 2019)

The impact of the top 10 articles by citations per year highlights a range that extends from 7.4 to almost 39.3 . These data take an intermediate value concerning the ranges determined in SLRs conducted on other topics and, in particular, are higher than Dumay et al. (2015) [range 8.64-12.46] and Bisogno et al. (2018) [range 11.0-17.3] and inferior to Cuozzo et al. (2016) [range 30.0-70.0]. The identification of the top 10 articles also allows us to answer the second part of the second research question ("Which kinds of contexts have been studied?"). Table 4 shows the findings. 
Table 4. Top 10 article's main findings.

\begin{tabular}{|c|c|c|c|c|}
\hline No. & Authors & Focus & $\begin{array}{l}\text { Findings: Areas of } \\
\text { impact }\end{array}$ & $\begin{array}{l}\text { Findings: Critical factors for } \\
\text { innovation }\end{array}$ \\
\hline 1 & $\begin{array}{l}\text { Barlow, J., } \\
\text { Bayer, S., } \\
\text { Curry, R. }\end{array}$ & $\begin{array}{l}\text { Analysis of complexity } \\
\text { factors in the } \\
\text { implementation of } \\
\text { remote assistance } \\
\text { services }\end{array}$ & $\begin{array}{l}\text { - Organizational change } \\
\text { (processes analysis of) } \\
\text { - Cost/effectiveness of } \\
\text { services to protect } \\
\text { patients' health outside } \\
\text { healthcare facilities } \\
\text { (short term+, } \\
\text { medium/long term-) }\end{array}$ & $\begin{array}{l}\text { - Organizational and cultural context } \\
\text { - Demand and ability to interpret the } \\
\text { users' needs - Complexity of the } \\
\text { project (the more patient dependent, } \\
\text { the more needs integration with the } \\
\text { health service - Local support - } \\
\text { Possibility to verify the effectiveness } \\
\text { - Ability of project managers to } \\
\text { identify key stakeholders and their } \\
\text { motivations and planning the needs } \\
\text { in a dynamic environment - Identify } \\
\text { potential users }\end{array}$ \\
\hline 2 & Petroni, A. & $\begin{array}{l}\text { Skills analysis in a } \\
\text { British multinational } \\
\text { medical device } \\
\text { manufacturer ( } 2018 \text {, } \\
\text { Gross revenue: } \$ 4.9 \\
\text { billion) }\end{array}$ & $\begin{array}{l}\text { Organizational design, } \\
\text { processes, and human } \\
\text { resources }\end{array}$ & $\begin{array}{l}\text { - Internal integration of skills (e.g., } \\
\text { skills change, coordination, } \\
\text { leadership) } \\
\text { - External integration of skills } \\
\text { (ability to identify and evaluate } \\
\text { options from external sources) }\end{array}$ \\
\hline 3 & $\begin{array}{l}\text { Auffray, C. } \\
\text { et al. }\end{array}$ & $\begin{array}{l}\text { Analysis of key factors } \\
\text { for the use of big data } \\
\text { in the healthcare sector } \\
\text { (by DNA sequencing) }\end{array}$ & $\begin{array}{l}\text { - Management of } \\
\text { "patient registries" for } \\
\text { their clinical } \\
\text { information potential to } \\
\text { monitor effectiveness } \\
\text { (and cost savings) in } \\
\text { care and improve health } \\
\text { policies at the macro } \\
\text { level }\end{array}$ & $\begin{array}{l}\text { - Systems technical organization } \\
\text { (lack of harmonization of data } \\
\text { format, processes, systems analysis, } \\
\text { transfer process between } \\
\text { institutions) } \\
\text { - Data protection and privacy } \\
\text { policies } \\
\text { - Cultural factors and training of key } \\
\text { actors }\end{array}$ \\
\hline 4 & Vest, J.R. & $\begin{array}{l}\text { Adoption of systems } \\
\text { for sharing health data } \\
\text { between institutions }\end{array}$ & $\begin{array}{l}\text { Preparation and change } \\
\text { of the technological, } \\
\text { organizational, and } \\
\text { environmental context }\end{array}$ & $\begin{array}{l}\text { Presence of technological and non- } \\
\text { technological barriers }\end{array}$ \\
\hline 5 & $\begin{array}{l}\text { Bernstein, } \\
\text { M.L., } \\
\text { McCreless, } \\
\text { T., Côté, } \\
\text { M.J. }\end{array}$ & $\begin{array}{l}\text { Constant analysis in } \\
\text { the implementation of } \\
\text { IT in the healthcare } \\
\text { sector }\end{array}$ & $\begin{array}{l}\text { IT investment } \\
\text { evaluation systems; IT } \\
\text { communication; Proper } \\
\text { planning of IT projects } \\
\text { (with goals and } \\
\text { strategies) }\end{array}$ & $\begin{array}{l}\text { - Improved use and maintenance of } \\
\text { dedicated budget (resource limits) } \\
\text { - Role of support leadership } \\
\text { - Use of project management, } \\
\text { implementation process, end-user } \\
\text { involvement }\end{array}$ \\
\hline 6 & $\begin{array}{l}\text { DeLuca, } \\
\text { J.M., } \\
\text { Enmark, R. }\end{array}$ & $\begin{array}{l}\text { Analysis of health } \\
\text { change factors for } \\
\text { eHealth }\end{array}$ & $\begin{array}{l}\text { Organizational and } \\
\text { public policy }\end{array}$ & $\begin{array}{l}\text { - Acceptance of change and } \\
\text { emerging business models } \\
\text { - Risk management, reliability of } \\
\text { manufacturers and products }\end{array}$ \\
\hline 7 & $\begin{array}{l}\text { Fonseca, } \\
\text { V.A., et. al. }\end{array}$ & $\begin{array}{l}\text { Continuous glucose } \\
\text { monitoring } \\
\text { systems/devices } \\
\text { (CGM) and reduction } \\
\text { of expenditure on acute } \\
\text { and chronic } \\
\text { complications } \\
\text { (hypoglycaemic crisis) }\end{array}$ & $\begin{array}{l}\text { Human factor, data } \\
\text { management processes, } \\
\text { reporting systems }\end{array}$ & $\begin{array}{l}\text { Metrics standardization for } \\
\text { reporting, user training, clinical } \\
\text { support management }\end{array}$ \\
\hline
\end{tabular}




\begin{tabular}{|c|c|c|c|c|}
\hline 8 & $\begin{array}{l}\text { Al-Qirim, } \\
\text { N. }\end{array}$ & $\begin{array}{l}\text { Implementation of } \\
\text { telemedicine in two } \\
\text { New Zealand health } \\
\text { organizations }\end{array}$ & $\begin{array}{l}\text { Planning and control } \\
\text { ability in supporting } \\
\text { cost/benefit analysis for } \\
\text { the assessment of } \\
\text { operating cost (need for } \\
\text { more rigorous } \\
\text { approaches in line with } \\
\text { the choice of new } \\
\text { technologies) }\end{array}$ & $\begin{array}{l}\text { - Identify contextual factors } \\
\text { (organizational, economic, political, } \\
\text { social, individual) to ensure the } \\
\text { success of innovation projects } \\
\text { - Isomorphism }\end{array}$ \\
\hline 9 & $\begin{array}{l}\text { Trueman, } \\
\text { P., } \\
\text { Grainger, } \\
\text { D.L., } \\
\text { Downs, } \\
\text { K.E. }\end{array}$ & $\begin{array}{l}\text { Analysis of the } \\
\text { conditions for using } \\
\text { coverage with evidence } \\
\text { development (CED) }\end{array}$ & $\begin{array}{l}\text { - Decision system (CED } \\
\text { aims to overcome } \\
\text { problems related to } \\
\text { decisions made in } \\
\text { conditions of } \\
\text { uncertainty, allowing a } \\
\text { conditional use of the } \\
\text { technology in } \\
\text { connection with the } \\
\text { development and } \\
\text { production of additional } \\
\text { evidence, from which } \\
\text { the benefits of the } \\
\text { investment are re- } \\
\text { assessed) } \\
\text { - Risk management (risk } \\
\text { sharing) } \\
\text { - Funding systems } \\
\text { (outcome-based } \\
\text { reimbursement } \\
\text { schemes) }\end{array}$ & $\begin{array}{l}\text { - Possibility to identify areas with } \\
\text { high clinical claims or to require } \\
\text { significant improvement in results } \\
\text { - Inadequacy of other hedging } \\
\text { instruments (e.g., cost-volumes- } \\
\text { results analysis) to solve the } \\
\text { uncertainty of cost-effectiveness } \\
\text { analysis } \\
\text { - Deal with stakeholders on the } \\
\text { terms of integration of the shreds of } \\
\text { evidence }\end{array}$ \\
\hline 10 & $\begin{array}{l}\text { Nilashi, } \\
\text { M., } \\
\text { Ahmadi, } \\
\text { H., Ahani, } \\
\text { A., } \\
\text { Ravangard, } \\
\text { R., } \\
\text { Ibrahim, } \\
\text { O.B. }\end{array}$ & $\begin{array}{l}\text { Analysis of factors } \\
\text { (success or inhibitors) } \\
\text { in the development of } \\
\text { hospital information } \\
\text { systems }\end{array}$ & $\begin{array}{l}\text { Technology, } \\
\text { environment, human } \\
\text { factor, organization } \\
\text { from an institutional } \\
\text { perspective }\end{array}$ & $\begin{array}{l}\text { - Compatibility and internal } \\
\text { complexity with respect to } \\
\text { innovation } \\
\text { - Presence of mimetic pressures (iso- } \\
\text { morphism) } \\
\text { - Manufacturer support }\end{array}$ \\
\hline
\end{tabular}

\section{Discussion}

The results allow us to develop some interesting considerations. The analysis of the articles of this SLR shows that the managerial implications of technological innovation in health have had a growing place in scientific journals, especially since the second half of 2000 and onward. The theme has attracted the interest of a diverse community; members are both academics from a multitude of disciplines (e.g., medical, engineering, economics) and professionals from various occupations (e.g., managers of government institutions, public healthcare organizations, pharmaceutical companies, electromedical equipment manufacturers). This circumstance can be explained by technological innovation itself requiring not only a design effort but also an implementation effort, which is conditional on overcoming barriers to changes of various kinds. According to Rogers' theoretical framework (1962), technology adoption is a five-stages process (knowledge, persuasion, decision implementation, and confirmation) in which a great number of conditions may inhibit the success of the adoption. In this regard, the literature has identified cultural (Auffrayet al., 2016; Barlow et al., 2006; Herzlinger, 2006; Jones \& Low, 2006; Loewe \& Dominiquini, 2006), managerial (Bernstein et al., 2007), organizational (Al-Qirim, 2007; Petroni, 1998; Barlow et al., 2006), political (Al-Qirim, 2007; Bernstein et al., 2007; Gask et al., 2002; Finch et al., 2003), economic (Bernstein et al., 2007), and technical obstacles (Herzlinger, 2006). 
Various researchers have highlighted that these obstacles, operating both individually and simultaneously, can impair the chances of disseminating technological innovations, even though the outputs are potentially well designed to meet user needs. This is compatible with the theme receiving growing interest from scholars whose papers are the result of research with authors from different professions.

The deepening of critical factors and the identification of how these can hinder the spread of IT represent a field of study where the academic community can make a significant contribution. A qualitative analysis of the contents of the publications selected in our dataset highlights that these describe the effects of technological products (e.g., an innovative care program) or process innovations (e.g., automation in the logistics of healthcare institutions), emphasizing technical-engineering, medical, cultural, and organizational conditions; more marginal managerial aspects are also considered.

It is common to believe that innovation can lead to cost savings, at least in the medium and long term, and more effective health care. However, several publications in the dataset did not detail the framing of the IT investment choices regarding the setup conditions of the strategic planning and management control system of health care organizations. Knowledge of these conditions would shed light on the strategic choices made in a given investment project in technological innovation. In the same way, the papers do not provide details on the problems and solutions related to the cost configurations used in choosing between alternative projects or on the distribution of costs and benefits in the medium and long term. Broader communication on the management control setup could facilitate practitioners' critical analysis when experimenting with the models proposed in the literature, also taking into account the complexity resulting from the multi-year duration of innovation projects. According to Al-Quirin (2007), at a professional level, the cost-benefit analysis should be conducted with more rigorous and consistent approaches than simply assessing the operating costs of new investment choices. Investment project assessment requires the use of differential costs analysis, while public healthcare organizations' reporting systems can be focused, indeed, on full costing configurations (e.g., for measuring health services' cost). Solovy and Chaiken (2003, p. 20) suggest that the management enlarge the definition of return on investment (ROI) used to evaluate the ROI in technological innovation to pay more attention to "intangible metrics in determining the business value of IT."

Further reflection should examine environmental contexts characterized by pressures linked to the contraction of public resources. In these contexts, such as those of the Eurozone, the financial constraints under which public healthcare systems currently operate often lead to decisions regarding technological innovation limited by short-term budgets rather than a longer-term view of their potential benefits.

From healthcare institutions' point of view, such contexts encourage management to better focus short-term prospects in the search for financial equilibrium. In this way, the possibility of evaluating and selecting projects like those of technological innovation in the public healthcare sector is significantly reduced, as their effectiveness must necessarily be weighted over a more extended period. Institutions responsible for protecting public health at the national and regional level play a central role in sustaining healthcare organizations in overcoming this limitation. Indeed, various authors have emphasized the need to face the innovation with "super-business" organizational models, creating ties with local and national "policy sponsors," and within public-private partnerships (Gask et al., 2002; Finch et al., 2003). Some scholars (Cobden et al., 2009; Di Matteo et al., 2007) have stressed the need for a rethink of the architecture of health systems, implementing a shift from models focused on disease care ("disease-centered model") to those that put the citizen/client at the center, for active promotion of the quality of life. This change would also provide more significant possibilities to spread those technological innovations that, according to the EC's (2017) call for public health future reforms, recognize patient centrality as a data source.

Concerning medical devices manufacturers, public financial constraints lead to sharp contractions in market demand and, consequently, a lower possibility of financing new investments for the development of new, more advanced solutions. The literature has reported, as a critical factor of success for IT investments, the possibility of involving endusers to influence the level of perceived utility and the perception of ease of use (Davis, 1989; Brand \& Huizingh, 2008); about obstacles, the difficulty of measuring demand and user needs is considered among the most challenging factors to overcome (Shaw, 1985; Rothwell, 1986; MacVaugh \& Schiavone, 2010). The possibility to train medical staff on new technologies also exists, as it does in the context of preparing for change at the organizational level (Al Quirim, 2007). This issue is also consistent with the theory's assumption regarding "diffusion of innovation" that the probability for success of investment in innovation is higher with the involvement of "opinion leaders" (Rogers, 1962). In the light of this theory, we believe that in a public financial constraints context, only a common strategy, capable of involving all key players in the health system, can enable technological innovations to be disseminated. 


\section{Conclusion}

With an SLR based on a mixed quantitative/qualitative approach, our study identifies the critical points for the research community studying the managerial reflexes of technological innovation in public healthcare organizations. To return a photograph of the studies, SLRs have the merit of analyzing large volumes of publications; these systematizations depend on the results of the initial selection. In our case, articles were extracted from SCOPUS, recognized as the largest database of peer-reviewed literature. Despite this choice, the extraction may have omitted scientific publications that have covered the subject of this research. This possibility can result in two cases: (a) at the time of data extraction, a singular journal was not listed on SCOPUS or (b) the journal was listed on SCOPUS after the publication of a paper potentially excluded from our analysis. Therefore, future research can repeat the extraction phase, either using additional keywords (e.g., telemedicine, eHealth) or other search engines (e.g., ISI Web of Science, EBSCOhost, Cochrane Library, PsycNet, MEDLINE).

Future investigations can also deepen the degree of cohesion in the scientific community by applying network analysis (NA). Initially developed as a tool for social research, this approach has also been used in scientific-mathematical studies (Scott, 1988). Without addressing the issue of paper quality, NA would allow scholars to study their cross citations, highlighting the reference publications (Wasserman \& Faust, 1994). The analysis can also be directed to break down the network into any cohesive "subgroups" (cliques) to verify interconnections within the various scientific reference areas (e.g., medical, engineering, economics).

With respect to processes to better manage the diffusion of innovation, our findings suggest that future studies should focus on the following issues: (a) Impact of innovations on management control systems and cost behavior patterns implemented in cost/benefit analyses for assessing the return in terms of efficiency and effectiveness; (b) Influence on personnel behavior and the improvement of decision-making capacity for the use of new technologies; (c) Changes in business administration processes needed to apply new technologies; (d) Organizational design of product innovation in health service customization; (e) Possible ways to form public-private partnerships and their effectiveness in ensuring the spread of IT investment.

\section{Funding}

This research received no specific grant from any funding agency in the public, commercial, or not-for-profit sectors.

\section{References (Note 1)}

Al-Qirim, N. (2007), "Championing telemedicine adoption and utilization in healthcare organizations in New Zealand", International journal of medical informatics, Vol. 76 No. 1, pp. 42-54.

Anell, A. (2005), "Swedish healthcare under pressure", Health economics, Vol. 14 No. S1, S237-S254.

Appleby, J. (2008), "The credit crisis and health care", Bmj, Vol. 337, a2259.

Atun, R.A., \& Sheridan, D. (2007), "Innovation in health care: The Engine of technological advances", International Journal of Innovation Management, Vol. 11 No. 02, v-x.

Auffray, C. et al. (2016), "Making sense of big data in health research: Towards an EU action plan", Genome medicine, Vol. 8No. 1, p. 71ff.

Ballantyne, G.H. (2002), "Robotic surgery, telerobotic surgery, telepresence, and telementoring", Surgical Endoscopy and Other Interventional Techniques, Vol. 16 No. 10, pp. 1389-1402.

Barlow, J., Bayer, S., \& Curry, R. (2006), "Implementing complex innovations in fluid multi-stakeholder environments: Experiences of 'telecare"', Technovation, Vol. 26 No. 3, pp. 396-406.

Bernstein, M.L., McCreless, T., \& Cote, M.J. (2007), "Five constants of information technology adoption in healthcare", Hospital Topics, Vol. 85 No. 1, pp. 17-25.

Bisogno, M., Dumay, J., Manes Rossi, F., \& Tartaglia Polcini, P. (2018), "Identifying future directions for IC research in education: a literature review", Journal of Intellectual Capital, Vol. 19 No. 1, pp. 10-33.

Blumenthal, D., \&Tavenner, M. (2010), "The 'meaningful use' regulation for electronic health records", New England Journal of Medicine, Vol. 363 No. 6, pp. 501-504.

Brand, M. J., \&Huizingh, E. K. (2008), "Into the drivers of innovation adoption", European Journal of Innovation Management, Vol. 11 No. 1, pp. 5-24.

Brandyberry, A.A. (2003), "Determinants of adoption for organisational innovations approaching saturation", European Journal of Innovation Management, Vol. 6 No. 3, pp. 150-158.

Broadbent, J., \& Guthrie, J. (2008), "Public sector to public services: 20 years of 'contextual' accounting research", Accounting, Auditing \& Accountability Journal, Vol. 21 No. 2, pp. 129-169. 
Cobden, D.S., Niessen, L.W., Barr, C.E., Rutten, F.F.H., \&Redekop, W.K. (2009), "Relationships among selfmanagement, patient perceptions of care, and health economic outcomes for decision-making and clinical practice in type 2 diabetes", Value in Health, Vol. 13, pp. 138-147.

Cochrane, A.L. (1972), Effectiveness and efficiency: random reflections on health services (Vol. 900574178), Nuffield Provincial Hospitals Trust, London.

Cook D.J., Mulrow, C.D. \& Haynes, R.B. (1997), "Systematic reviews: Synthesis of best evidence for clinical decision", Annals of Internal Medicine, Vol. 126 No. 5, pp. 376-380.

Cooper, H. (2010), Research Synthesis and Meta-Analysis, 4th ed., Sage Publications, Thousand Oaks, CA.

Cresswell, K., \& Sheikh, A. (2013), "Organizational issues in the implementation and adoption of health information technology innovations: an interpretative review", International journal of medical informatics, Vol. 82 No. 5 , pp. e73-e86.

Cuozzo, B., Dumay, J., Palmaccio, M., \& Lombardi, R. (2017), "Intellectual capital disclosure: a structured literature review", Journal of Intellectual Capital, Vol. 18 No. 1, pp. 9-28.

Davis, F. (1989), "Perceived usefulness, perceived ease of use, and user acceptance of information technology", MIS Quarterly, Vol. 13 No. 3, pp. 319-340.

Deluca, J.M., \&Enmark, R. (2000), "E-health: the changing model of healthcare", Frontiers of health services management, Vol. 17 No. 1, p. 3 ff.

Denyer, D. \&Tranfield, D. (2008), Producing a systematic review, in D. Buchanan (Ed.), The sage handbook of organizational research methods (pp. 671-689), London, Sage.

Di Matteo, M.R., Haskard, K.B., \& Williams, S.L. (2007), "Health beliefs, disease severity, and patient adherence: a meta-analysis", Medical Care, Vol. 45, pp. 521-528.

Dumay, J., Bernardi, C., Guthrie, J., \&Demartini, P. (2016), "Integrated reporting: A structured literature review", Accounting Forum, Vol. 40 No. 3, pp. 166-185.

Dumay, J., de Villiers, C., Guthrie, J., \& Hsiao, P.C. (2018), "Thirty years of Accounting, Auditing and Accountability Journal: A critical study of the journal's most cited articles", Accounting, Auditing \& Accountability Journal, 31(5), pp. 1510-1541.

Dumay, J., Guthrie, J., \& Puntillo, P. (2015), "IC and public sector: A structured literature review", Journal of Intellectual Capital, Vol. 16 No.2, pp. 267-284.

Ekeland, A.G., Bowes, A., \&Flottorp, S. (2010), "Effectiveness of telemedicine: a systematic review of reviews", International journal of medical informatics, Vol. 79No.11, pp. 736-771.

England, I., \& Stewart, D. (2007), "Executive management and IT innovation in health: identifying the barriers to adoption", Health Informatics Journal, Vol. 13 No. 2, pp. 75-87.

European Commission (2015), Commission Staff Working Document "A Digital Single Market Strategy for Europe Analysis and Evidence", SWD(2015) 100 final, 6.5.2015.

European Commission (DG ECFIN)-EPC (AWG) (2015b), The 2015 Ageing Report - Economic and budgetary projections for the 28 EU Member States (2013-2060).

European Commission (2016), Joint Report on Health Care and Long-Term Care Systems \& Fiscal Sustainability, Institutional Paper 037, October.

European Commission (2017), State of Health in the UE: Companion Report 2017.

European Commission (2018a), Commission Staff Working Document, Accompanying the document Communication from the Commission to the European Parliament, the Council, the European Economic and Social Committee and the Committee or the Regions on enabling the digital transformation of health and care in the Digital Single Market; empowering citizens and building a healthier society, $\operatorname{SWD}(2018) 126$ final, 25.4.2018.

European Commission (2018b), Communication from the Commission to the European Parliament, the Council, the European Economic and Social Committee and the Committee or the Regions on enabling the digital transformation of health and care in the Digital Single Market; empowering citizens and building a healthier society, $\operatorname{COM}(2018) 233$ final, 25.4.2018.

Finch, T., May, C., Mair, F., Mort, M., \& Gask, L. (2003), "Integrating service development with evaluation in telehealthcare: an ethnographic study", British Medical Journal, Vol. 327, pp. 1205-1209.

Fonseca, V. A., Grunberger, G., Anhalt, H., Bailey, T. S., Blevins, T., Garg, S. K., ... \& Tamborlane, W. (2016), "Continuous glucose monitoring: a consensus conference of the American Association of Clinical Endocrinologists and American College of Endocrinology", Endocrine Practice, Vol. 22 No. 8, pp. 10081021.

Freeman, R., \& Moran, M. (2000), "Reforming health care in Europe", West European Politics, Vol. 23 No. 2, pp. 3558. 
Gask, L., Harrison, R., MacFarlane, A., Mair, F., May, C., Wallace, P., \& Williams, T. (2002), Telemedicine Adoption Study Group: predicting the normalization of telemedicine services through qualitative evaluation, Proceedings: Royal Society of Medicine Symposium on Telemedicine and eHealth, 29 May 2002.

Gonçales Filho, M., Campos, F.C.D., \&Assumpção, M.R.P. (2016), "Systematic literature review with bibliometric analysis on Lean Strategy and manufacturing in industry segments", Gestão\&Produção, Vol. 23 No. 2, pp. 408-418.

Graffigna G., Barello S., Wiederhold B.K., Bosio A.C., \& Riva G. (2013), "Positive technology as a driver for health engagement", Studies in Health Technology and Informatics, pp. 9-17.

Grant, M.J., \& Booth, A. (2009), "A typology of reviews: an analysis of 14 review types and associated methodologies", Health Information \& Libraries Journal, Vol. 26 No. 2, pp. 91-108.

Hamet, P., \& Tremblay, J. (2017), “Artificial intelligence in medicine”, Metabolism, Vol. 69, pp. S36-S40.

Herzlinger, R.E. (2006), "Why innovation in health care is so hard", Harvard business review, Vol. 84 No.5, p. $58 \mathrm{ff}$.

Kerr, D., Axelrod, C., Hoppe, C., \&Klonoff, D.C. (2018), "Diabetes and technology in 2030: a utopian or dystopian future?", Diabetic Medicine, Vol. 35 No.4, pp. 498-503.

Jha, A.K., DesRoches, C.M., Campbell, E.G., Donelan, K., Rao, S.R., Ferris, T.G., ... \& Blumenthal, D. (2009), "Use of electronic health records in US hospitals", New England Journal of Medicine, Vol. 360 No. 16, pp. 16281638.

Jones, S., \& Low, G. (2006), The labour of learning: a framework for understanding knowledge barriers in IT innovation, ACIS 2006 Proceedings. 89.

Jordan, T., \&Battaglio, R.P. (2014), "Are we there yet? The state of public human resource management research", Public Personnel Management, Vol. 43 No. 1, pp. 25-57.

Loewe, P., \&Dominiquini, J. (2006), "Overcoming the barriers to effective innovation”, Strategy \& leadership, Vol. 34 No.1, pp. 24-31.

MacLure, K., Stewart, D., \&Strath, A. (2014), “A systematic review of medical and non-medical practitioners” views of the impact of ehealth on shared care", European Journal of Hospital Pharmacy: Science and Practice, Vol. 21 No.1, pp. 54-62.

MacVaugh, J., \& Schiavone, F. (2010), "Limits to the diffusion of innovation. A literature review and integrative model", European journal of innovation management, Vol. 13 No. 2, pp. 197-221.

Massaro, M., Dumay, J., \&Garlatti, A. (2015), "Public sector knowledge management: a structured literature review", Journal of Knowledge Management, Vol. 19 No. 3, pp. 530-558.

Massaro, M., Dumay, J., \& Guthrie, J. (2016), "On the shoulders of giants: undertaking a structured literature review in accounting”, Accounting, Auditing \& Accountability Journal, Vol. 29 No. 5, pp. 767-801.

Massaro, M., Handley, K., Bagnoli, C., \& Dumay, J. (2016), "Knowledge management in small and medium enterprises: a structured literature review", Journal of Knowledge Management, Vol. 20 No. 2, pp. 258-291.

Metcalf, D., Milliard, S.T., Gomez, M., \& Schwartz, M. (2016), "Wearables and the internet of things for health: Wearable, interconnected devices promise more efficient and comprehensive health care", IEEE pulse, Vol. 7 No. 5, pp. 35-39.

Moher, D., Liberati, A., Tetzlaff, J., Altman, D.G., The PRISMA Group (2009), "Preferred Reporting Items for Systematic Reviews and Meta-Analyses: The PRISMA Statement", Annals of internal medicine, Vol. 151 No. 4, pp. 264-269.

Mulrow, C. (1994), "Rationale for systematic reviews", BMJ. British medical journal, Vol. 309 No. 6954, pp. 597-599.

Murdoch, T.B., \&Detsky, A.S. (2013), "The inevitable application of big data to health care", Jama, Vol. 309 No. 13, pp. 1351-1352.

Nilashi, M., Ahmadi, H., Ahani, A., Ravangard, R., \& Bin Ibrahim, O. (2016), "Determining the importance of hospital information system adoption factors using fuzzy analytic network process (ANP)", Technological Forecasting and Social Change, Vol. 111, pp. 244-264.

Oh, H., Rizo, C., Enkin, M., \&Jadad, A. (2005), "What is eHealth (3): a systematic review of published definitions", Journal of medical Internet research, Vol. 7 No. 1, e1.

Orszag, P.R., \& Emanuel, E.J. (2010), "Health care reform and cost control", $N$ Engl J Med, Vol. 363 No. 7, pp. 601603.

Pauget, B., \& Wald, A. (2018), "Creating and implementing organizational innovation", European Journal of Innovation Management, Vol. 21 No. 3, pp. 384-401.

Perednia, D.A., \& Allen, A. (1995), "Telemedicine technology and clinical applications", Jama, Vol. 273 No. 6, pp. 483-488.

Petroni, A. (1998), "The analysis of dynamic capabilities in a competence-oriented organization”, Technovation, Vol. 18 No. 3, pp. 179-189. 
Pitsillides, A., Pitsillides, B., Samaras, G., Dikaiakos, M., Christodoulou, E., Andreou, P., \& Georgiadis, D. (2006), DITIS: A collaborative virtual medical team for home healthcare of cancer patients, in M-Health (pp. 247266), Springer, Boston, MA.

Popescu, G.H. (2014), "Economic aspects influencing the rising costs of health care in the United States", American Journal of Medical Research, Vol. 1 No. 1, pp. 47-52.

Rogers, E.M. (1962), Diffusion of Innovations, Free Press, New York, NY.

Roine, R., Ohinmaa, A., \& Hailey, D. (2001), "Assessing telemedicine: a systematic review of the literature", Cmaj, Vol. 165 No. 6, pp. 765-771.

Rothstein, H.R., \& Hopewell, S. (2009), Grey Literature, in The Handbook of Research Synthesis and Meta-Analysis, edited by Cooper, H., Larry V.

Rothwell, R. (1986), "Public innovation policy: to have or to have not?", $R \& D$ Management, Vol. 16 No. 1, pp. 25-36.

Schultz, C., Zippel-Schultz, B. and Salomo, S. (2012), "Hospital innovation portfolios: key determinants of size and innovativeness", Health Care Management Review, Vol. 37 No. 2, pp. 132-143.

Scott, J. (1988), "Social network analysis", Sociology, Vol. 22 No. 1, pp. 109-127.

Shaw, B. (1985), "The role of the interaction between the user and the manufacturer in medical equipment innovation", $R \& D$ Management, Vol. 15, pp. 283-292.

Solovy, A., Chaiken, B. (2003), "ROI under scrutiny: The radical redefinition of a core concept", Frontiers of Health Services Management, Vol. 19 No. 3, pp. 17-28.

Spender, J.C., Corvello, V., Grimaldi, M., \&Rippa, P. (2017), "Startups and open innovation: a review of the literature", European Journal of Innovation Management, Vol. 20 No. 1, pp. 4-30.

Tam, W.W., Lo, K.K., \&Khalechelvam, P. (2017), "Endorsement of PRISMA statement and quality of systematic reviews and meta-analyses published in nursing journals: a cross-sectional study", BMJ open, Vol. 7 No. 2, pp. $1-8$.

Trueman, P., Grainger, D.L., \& Downs, K.E. (2010), "Coverage with evidence development: applications and issues", International journal of technology assessment in health care, Vol. 26 No. 1, pp. 79-85.

Vest, J.R. (2010), "More than just a question of technology: Factors related to hospitals' adoption and implementation of health information exchange", International journal of medical informatics, Vol. 79 No. 12, pp. 797-806.

Walther, J.B., Pingree, S., Hawkins, R.P., \& Buller, D.B. (2005), "Attributes of interactive online health information systems", Journal of Medical Internet Research, Vol. 7 No. 3, e33.

Wasserman, S., \& Faust, K. (1994), Social Network Analysis: Methods and Applications, Cambridge University Press, Cambridge, UK.

Whitten, P.S., Mair, F.S., Haycox, A., May, C.R., Williams, T.L., \&Hellmich, S. (2002), "Systematic review of cost effectiveness studies of telemedicine interventions", Bmj, Vol. 324 No. 7351, pp. 1434-1437.

World Health Organization (2006), Building Foundations for eHealth. Progress of Member States, WHO press, Geneva.

Xu, X., Chen, X., Jia, F., Brown, S., Gong, Y., Xu, Y. (2018), "Supply chain finance: A systematic literature review and bibliometric analysis", International Journal of Production Economics, Vol. 204 No. 10, pp. 70-82.

Notes

Note 1. The bibliography does not contain references to the literature revised, except for "Top ten articles". 